\title{
SILVER DOPING OF SILICA-HAFNIA WAVEGUIDES CONTAINING TB3+/YB3+ RARE EARTHS FOR DOWNCONVERSION IN PV SOLAR CELLS
}

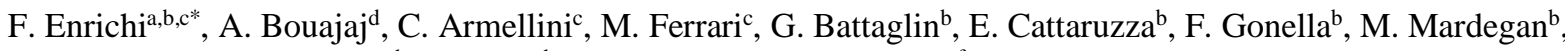

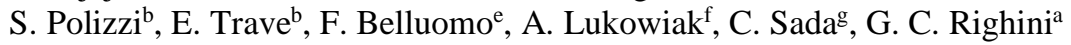 \\ ${ }^{a}$ Museo Storico della Fisica e Centro Studi e Ricerche Enrico Fermi, Piazza del Viminale 1, 00184 Roma, Italy \\ ${ }^{b}$ Dipartimento di Scienze Molecolari e Nanosistemi, Università Ca' Foscari Venezia, via Torino 155/b, 30172 \\ Mestre, Venezia, Italy \\ ${ }^{c}$ CNR-IFN, Istituto di Fotonica e Nanotecnologie, CSMFO Lab. \& FBK-CMM, Via alla Cascata 56/C, 38123 \\ Povo, Trento, Italy \\ ${ }^{d}$ Laboratoire des Technologies Innovantes, LTI, Département de Génie industriel ENSA - Tanger. Université \\ Abdelmalek Essaâdi. Tanger, Morocco. \\ ${ }^{e}$ Meridionale Impianti SpA, Via Senatore Simonetta 26/D, 20867 Caponago, Monza Brianza, Italy \\ ${ }^{f}$ Institute of Low Temperature and Structure Research, PAS, ul. Okolna 2, 50-422 Wroclaw, Poland \\ ${ }^{g}$ Dipartimento di Fisica G. Galilei, Università di Padova, Via Marzolo 8, 35131 Padova, Italy
}

\begin{abstract}
The aim of this paper is to study the possibility to obtain an efficient downconverting waveguide which combines the quantum cutting properties of $\mathrm{Tb}^{3+} / \mathrm{Yb}^{3+}$ codoped materials with the optical sensitizing effects provided by silver nanoaggregates. The preparation of $70 \mathrm{SiO}_{2}-30 \mathrm{HfO}_{2}$ glass and glass-ceramic waveguides by sol gel route, followed by Ag ion-exchange method is reported. The films were subsequently annealed to induce the migration and aggregation of the metal ions. Results of compositional and optical characterization are given, providing evidence for the successful introduction of $\mathrm{Ag}$ in the films, while the photoluminescence emission is strongly dependent on the annealing conditions. These films can find potential applications as downshifting layers to increase the efficiency of PV solar cells.
\end{abstract}

\section{Introduction}

Solar energy has the great advantage of being inextinguishable, widely available across the planet and relatively cheap. Moreover, solar energy exploitation produces little or no wastes such as carbon dioxide or other chemical pollutants, thus having minimal environmental impact. For these reasons, strong efforts and research investments are devoted to improve their efficiency. Among solar exploitation systems, photovoltaic devices (PV) relies in the capability of the active material in absorbing light and generating charge carriers, and in the subsequent extraction of these carriers. However, despite significant progress, the performance of PV cells is still low, leading to a cost/watt higher than the cost of traditional energy. For this reason, the evolution for the "next generation" solar cells is based on the high photoconversion efficiency (PCE) per unit area, with the theoretical possibility to approach the thermodynamic limit up to $93 \%$ [1]. However, one of the major limitations to the efficiency of solar cell devices is the mismatch between the spectral sensitivity of the active material and the solar spectrum, which is responsible for the loss of a significant part of radiation. Indeed, the absorption of radiation in photovoltaic solar cells is spectrally controlled by the bandgap $\left(\mathrm{E}_{\mathrm{g}}\right)$ of the semiconductor material. For crystalline silicon (c-Si) solar cells, this corresponds to $1127 \mathrm{~nm}\left(\mathrm{E}_{\mathrm{g}}=1.1 \mathrm{eV}\right)$. Radiation with energy lower than the bandgap is not absorbed because it is not able to generate electron-hole pairs and it is lost. Radiation with energy higher than the gap is also not efficient because most of the energy is lost in internal thermalization processes or it is absorbed in the superficial region and the generated charge couples can recombine at surface defect states. Therefore, a way towards high efficiency devices is to improve the match between the solar spectrum and cell's absorption properties either by adjusting the band gap of the semiconductors to the solar spectrum, like in multi-junction cells, or by modifying the spectrum of the light that reaches the cell. The latter approach uses luminescent materials to transfer as much of the solar photon energies to the region of maximum absorption and efficiency of the device [2, 3, 4], close to the bandgap of the semiconductor. Rare earth (RE) ions are good luminescent candidates for this task $[5,6]$, due to their wide variety of electronic levels, and $\mathrm{Yb}^{3+}$ ions are particularly suited for c-Si solar cells, due to the ${ }^{2} \mathrm{~F}_{5 / 2} \rightarrow{ }^{2} \mathrm{~F}_{7 / 2}$ transition which gives a NIR emission around $1000 \mathrm{~nm}$. Moreover, co-doping with other RE ions has been widely studied for the possibility to enhance the $\mathrm{Yb}^{3+}$ efficiency via energy transfer and quantum cutting $[7,8,9]$ and nanostructured RE doped glass-ceramics are among the most promising host materials for optical and photovoltaic applications $[10,11,12,13,14]$. In

\footnotetext{
* Corresponding author email: francesco.enrichi@unive.it
} 
previous studies we used the sol gel method to develop RE doped silica-hafnia waveguides. In silica-hafnia glass-ceramics the rare earth ions are embedded in hafnia nanocrystals which have a cut-off frequency of about $700 \mathrm{~cm}^{-1}$. Therefore the presence of hafnia nanocrystal produces a strong reduction of the non-radiative transition process reflected by a lengthening of the measured emission lifetime. Moreover, the sol gel preparation of silica-hafnia waveguides is a reliable and flexible system that was already proven to be suitable for rare earth doping $[15,16]$. Previous studies on $70 \mathrm{SiO}_{2}-30 \mathrm{HfO}_{2}$ downconverting waveguides by $\mathrm{Tb}^{3+}-\mathrm{Yb}^{3+}$ codoping have already demonstrated to allow very high transfer efficiencies up to $55 \%[17,18]$. Unfortunately these systems are still limited by the small absorption cross section and specific wavelengths of the RE ions involved, which limit the final performance of the process, while a strong and broadband conversion would be desirable, allowing the high efficiency conversion of a much wider part of the solar spectrum, in particular in the UV region, where the PV efficiency of the solar cell is small. A possible approach towards broadband and efficient energy conversion is the use of the energy transfer from semiconductor or metal nanostructures or nanocrystals to the RE ions. Noteworthy, this is not related to the exploitation of plasmonic effects [19, 20], but rather to an efficient absorption followed by Föster energy transfer, which was widely investigated for $\mathrm{Er}^{3+}$ doped waveguide optical amplifiers $[21,22,23,24,25,26]$, but never applied to $\mathrm{Tb}^{3+} \mathrm{Yb}^{3+}$ codoped glass ceramic waveguides for PV enhancement, to our knowledge.

In this paper we combine the quantum cutting optical properties of rare-earth doped materials with broadband absorption and emission properties of silver aggregates such as dimers, trimers or small multimers [27] (extended reviews on $\mathrm{Ag}$ ion-exchange can be found in refs. [28, 29, 30]). We report the synthesis and characterization of $\mathrm{Ag}$ exchanged $\mathrm{Tb}^{3+}-\mathrm{Yb}^{3+}$ codoped glass and glass ceramic waveguides, focusing on the structural and optical properties of the obtained materials and on their potential application for high efficiency PV solar cells.

\section{Experimental}

Two series of $70 \mathrm{SiO}_{2}-30 \mathrm{HfO}_{2}$ samples in form of glass (G) or glass-ceramics (GC), depending on the final annealing treatment at $900{ }^{\circ} \mathrm{C}$ or $1000{ }^{\circ} \mathrm{C}$ respectively, were activated by different molar concentrations of terbium and ytterbium ions and prepared by a sol-gel route using the dip-coating technique, keeping constant the rate $[\mathrm{Yb}] /[\mathrm{Tb}]=4$, following the experimental procedure described in [18]. Silica-hafnia films were deposited on cleaned pure $\mathrm{SiO}_{2}$ substrates and the final films, obtained after 20 dips, were stabilized by a treatment of 5 min in air at $900{ }^{\circ} \mathrm{C}$. As a result of the procedure, transparent and crack-free films were obtained (TY-G sample). To obtain GC samples, an additional heat treatment was performed in air at a temperature of $1000{ }^{\circ} \mathrm{C}$ for $30 \mathrm{~min}$ in order to nucleate hafnia nanocrystals inside the film (TY-GC sample). $70 \mathrm{SiO}_{2}-30 \mathrm{HfO}_{2} \mathrm{GC}$ planar waveguides doped with rare earth ions were thus produced. A glass sample with only $\mathrm{Tb}$ and without $\mathrm{Yb}$ was also prepared (T0-G).

To introduce silver in the $\mathrm{Tb} / \mathrm{Yb}$ codoped waveguides, $\mathrm{Ag}^{+}$ion exchange was performed by immersing the samples in a molten salt bath $\left(1 \mathrm{~mol} \%\right.$ of $\mathrm{AgNO}_{3}$ in $\left.\mathrm{NaNO}_{3}\right)$. The bath temperature was $350^{\circ} \mathrm{C}$, for $1 \mathrm{~h}$ of immersion duration. In order to favour the formation of small $\mathrm{Ag}$ aggregates, different annealings in air were performed after the silver doping: $1 \mathrm{~h}$ at $380^{\circ} \mathrm{C}$ or $1 \mathrm{~h}$ at $440^{\circ} \mathrm{C}$. The sample labels, their thickness and refractive index at $544 \mathrm{~nm}$ and $632 \mathrm{~nm}$ are reported in table 1.

The thickness of the waveguides and the refractive index at 544 and $632 \mathrm{~nm}$ were obtained by a variable angle Woollam V-VASE spectroscopic ellipsometer. Elemental profiling was done by Secondary Ion Mass Spectroscopy (SIMS) in ultra-high vacuum conditions at different primary beam intensities (50 nA and $75 \mathrm{nA})$ rastering over a nominally $125 \times 125 \mu \mathrm{m}^{2}$ area. The beam-blanking mode was used to improve the depth resolution, interrupting the sputtering process during magnet stabilization periods. The dependence of the erosion speed on the matrix composition was taken into account by measuring the erosion speed at various depths in each sample. The erosion speed was then evaluated by measuring the depth of the erosion crater at the end of each analysis by means of a Tencor Alpha Step profilometer with a maximum uncertainty of a few nanometers. The measurements were performed in high mass resolution configuration to avoid mass-interference artefacts.

The charge build-up while profiling the insulating samples was compensated by an electron gun without any need to cover the surface with a metal film.

Elemental concentration was obtained by Rutherford Backscattering Spectrometry (RBS) at INFN-Legnaro National Laboratories by using a $2.0 \mathrm{MeV}^{4} \mathrm{He}^{+}$beam (backscattering angle $=160$ degrees). The diffused atoms concentration was calculated by simulating the RBS spectra with the RUMP code.

Photoluminescence characterization was performed by a Horiba JobinYvon Fluorolog-3 spectrofluorimeter, able to perform PL, PLE and time resolved PL measurements both in solid and liquid samples in the whole range of UV-VIS-NIR wavelengths (from $250 \mathrm{~nm}$ to $1700 \mathrm{~nm}$ ). The light of a 450W Xenon lamp excites the sample after passing a double-grating Czerny-Turner monochromator to select the desired wavelength. The optical emission of the sample is analysed by a single grating monochromator coupled to a suitable detector: a Hamamatsu PMT R928 for measurements between $185 \mathrm{~nm}$ and $900 \mathrm{~nm}$ or a PMTR5509-73 for measurements up to $1700 \mathrm{~nm}$. 
Table 1: samples labels, their thickness and refractive index at $544 \mathrm{~nm}$ and $632 \mathrm{~nm}$

\begin{tabular}{|c|c|c|c|c|c|c|c|}
\hline $\begin{array}{c}\text { label } \\
\text { sample }\end{array}$ & $\mathrm{Ag}$ & $\begin{array}{c}{[\mathrm{Tb}]} \\
\mathrm{mol} \%\end{array}$ & $\begin{array}{c}{[\mathrm{Yb}]} \\
\mathrm{mol} \%\end{array}$ & $\begin{array}{c}\text { Annealing } \\
\mathrm{T}\left({ }^{\circ} \mathrm{C}\right)\end{array}$ & $\begin{array}{c}\text { Thickness } \\
(\mathrm{nm})\end{array}$ & $\mathrm{n} @ 544$ & $\mathrm{n} @ 632$ \\
\hline T0-G & - & 1 & 0 & - & $704.8 \pm 0.4$ & 1.626 & 1.621 \\
\hline T0-G-A & $\checkmark$ & 1 & 0 & - & $663.9 \pm 1.4$ & 1.670 & 1.662 \\
\hline T0-G-B & $\checkmark$ & 1 & 0 & 380 & $663.6 \pm 1.3$ & 1.684 & 1.675 \\
\hline T0-G-C & $\checkmark$ & 1 & 0 & 440 & $669.9 \pm 1.1$ & 1.666 & 1.658 \\
\hline \multicolumn{7}{|l|}{} \\
\hline TY-G & - & 1 & 4 & - & $708.7 \pm 0.5$ & 1.641 & 1.634 \\
\hline TY-G-A & $\checkmark$ & 1 & 4 & - & $696.0 \pm 0.9$ & 1.678 & 1.673 \\
\hline TY-G-B & $\checkmark$ & 1 & 4 & 380 & $672.9 \pm 0.8$ & 1.709 & 1.703 \\
\hline TY-G-C & $\checkmark$ & 1 & 4 & 440 & $687.9 \pm 0.9$ & 1.700 & 1.697 \\
\hline \multicolumn{7}{|l|}{} \\
\hline TY-GC & - & 1 & 4 & - & $654.4 \pm 0.8$ & 1.677 & 1.672 \\
\hline TY-GC-A & $\checkmark$ & 1 & 4 & - & $661.5 \pm 0.5$ & 1.676 & 1.671 \\
\hline TY-GC-B & $\checkmark$ & 1 & 4 & 380 & $652.0 \pm 1.0$ & 1.693 & 1.689 \\
\hline TY-GC-C & $\checkmark$ & 1 & 4 & 440 & $653.5 \pm 1.0$ & 1.683 & 1.678 \\
\hline
\end{tabular}

\section{Result and discussion}

\subsection{Structural investigation}

The structural investigation of the glass and glass-ceramic samples was already reported in [18], demonstrating the formation of few nanometre sized $\mathrm{HfO}_{2}$ nanocrystals in an amorphous silica matrix only after $1000{ }^{\circ} \mathrm{C}$ annealing treatments (TY-GC series), while the matrix remains amorphous for $900{ }^{\circ} \mathrm{C}$ annealing (T0-G and TY$\mathrm{G}$ series). As an example, in Fig. 1 the RBS analysis of the T0-G-A as-exchanged sample is shown, with the corresponding simulation curve. The curve is in perfect agreement with the nominal composition of the material and attests the presence of a small, but measurable, amount of $\mathrm{Ag}$ of the order of $(0.2 \pm 0.1)$ at.\%. After annealing the presence of $\mathrm{Ag}$ was strongly reduced. For all the glass-ceramic samples $\mathrm{Ag}$ was not detectable at all.
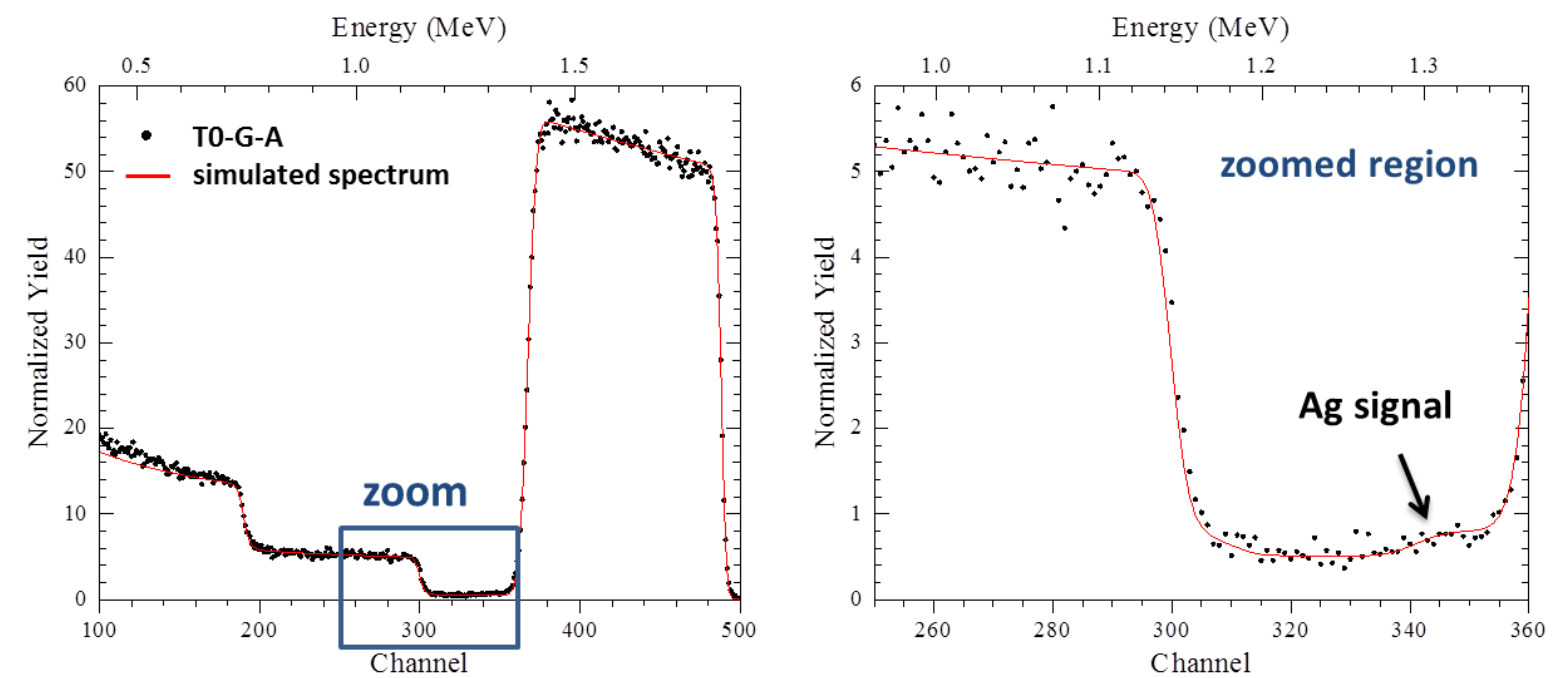

Figure 1: RBS spectrum of T0-G-A sample and corresponding simulation curve. On the right, the zoomed region points out the presence of a small 0.2 at.\% amount of Ag.

The observed behaviour was confirmed by SIMS analysis. As an example, the elemental profiles acquired for the T0-G-A sample are reported in Fig. 2. For each element, the signal is proportional to the concentration and the integral of the curve is proportional to the total amount of the specific element. In the figure, the 
waveguide/substrate interface is also indicated as a vertical dashed line. The thicknesses of the waveguides evaluated by SIMS are in agreement with the ellipsometric measurements reported in Table 1.

The measurements on the glass samples confirm the homogeneous introduction of Ag in the whole depth of the waveguide. However, since the distribution of other elements is unchanged, this cannot be ascribed to an ionexchange process, but rather to a thermal diffusion. The mobility of $\mathrm{Ag}$ in the glass is also confirmed by SIMS measurements on the samples before and after the annealing treatments. Indeed, after the annealings at $380{ }^{\circ} \mathrm{C}$ and $440{ }^{\circ} \mathrm{C}$, the $\mathrm{Ag}$ depth profile does not change its shape but the total amount of silver decreases at the $40 \%$ of the starting value, probably due to an outdiffusion process, while the amounts of other elements are unchanged. A completely different behaviour was found for glass ceramic samples, where the Ag signal was not detected. It is worth observing that the previous results are in perfect agreement with RBS measurements. This could be expected from the fact that the GC samples are more compact than the glassy ones, therefore Ag ions can enter more easily in the material.

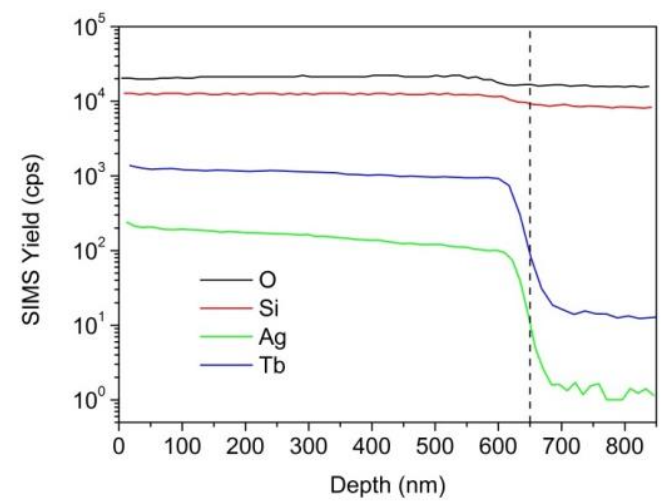

Figure 2: SIMS elemental profiles for the T0-G-A sample, with indication of the waveguide/substrate interface.

\subsection{Optical and photoluminescence analysis}

The optical characterization results for the prepared samples in terms of refractive index and thickness of the waveguides obtained by ellipsometry are reported in Table 1 . The waveguides have a thickness between 0.6 and $0.7 \mu \mathrm{m}$ and their refractive index confirms what observed by the previous structural analysis. Indeed the ionexchange process is more effective for the G samples, attested by a significant stronger increasing of the index of refraction, while it has a relatively small effect on the GC samples, where the index of refraction is almost unchanged.

The photoluminescence excitation and emission spectrum from $\mathrm{Ag}$ aggregates can provide information concerning the metal clusterization process [31] and the analysis of $\mathrm{Tb}^{3+}$ and $\mathrm{Yb}^{3+}$ emissions can be used to detect the occurrence of possible sensitization, enhancement and energy transfer from Ag nanoaggregates to the rare earth ions.

Fig. 3 reports the PL emission in the visible region of TY-G and TY-GC series of samples before and after Ag introduction and annealing. The intense emission from ${ }^{5} \mathrm{D}_{4} \rightarrow{ }^{7} \mathrm{~F}_{5} \mathrm{~Tb}^{3+}$ transition at $543.5 \mathrm{~nm}$ can be clearly detected. Moreover, only for the $\mathrm{G}$ samples, a very intense broadband emission in the violet-blue spectral region appears after the Ag-exchange process as the dominant feature, but it is strongly reduced after annealing. In agreement with SIMS, RBS and ellipsometry measurements, we can reasonably attribute the appearing of this emission in relation to the introduction of $\mathrm{Ag}$ in the matrix. In particular the band presents two emission peaks at $415 \mathrm{~nm}$ and $436 \mathrm{~nm}$. Further luminescence investigation is reported in Fig. 4 by exciting the samples at $280 \mathrm{~nm}$ wavelength. It is worth observing that the spectral emission of the violet-blue band is unchanged. Based on literature studies [32, 33, 34], the emission at $415 \mathrm{~nm}$ is usually associated to isolated $\mathrm{Ag}^{+}$ions, while the $436 \mathrm{~nm}$ emission can be due to $\mathrm{Ag}^{+}$in a different site or to $\mathrm{Ag}^{+}-\mathrm{Ag}^{+}$dimers. The presence of multimers or initial clustering stages gives additional features in the green-red spectral region. In our samples, due to the very low $\mathrm{Ag}$ concentration, we can expect that $\mathrm{Ag}$ is mainly isolated, while the presence of multimers could be reasonably excluded, in agreement with the observed spectral features. After annealing, a significant outdiffusion of $\mathrm{Ag}$ from the sample, attested by SIMS, and a general rearrangement of the matrix can explain the disappearance of the PL emission band.

The analysis on the GC sample series reports only the spectral emission features related to ${ }^{5} \mathrm{D}_{4} \rightarrow{ }^{7} \mathrm{~F}_{J}(J=2-6)$ transitions of $\mathrm{Tb}^{3+}$ ions, due to the inefficient introduction of silver in the glass-ceramic matrix.

The PLE spectra for the G and GC samples are reported in Fig. 5 and Fig. 6 respectively for two different emission wavelengths, at $450 \mathrm{~nm}$ and at $543.5 \mathrm{~nm}$ emission. When $543.5 \mathrm{~nm}$ is used, the typical direct excitation peaks of $\mathrm{Tb}^{3+}$ ions are detected. Only for the TY-G-A sample, a broad excitation band is also present. This band is much higher and better studied at $450 \mathrm{~nm}$, with a maximum at $366 \mathrm{~nm}$ and a second shoulder around $280 \mathrm{~nm}$, 
which can be associated to the previously discussed $\mathrm{Ag}^{+}$ions and dimers. The band is widely extended in the whole UV region up to $420 \mathrm{~nm}$ and could provide a significant contribution for enhancing the efficiency of solar cells, downshifting the solar spectrum from UV to the visible and, combined with $\mathrm{Tb}^{3+}$ and $\mathrm{Yb}^{3+}$ rare earth ions it can further shift the emitted wavelength to the region of best absorption of the cell.
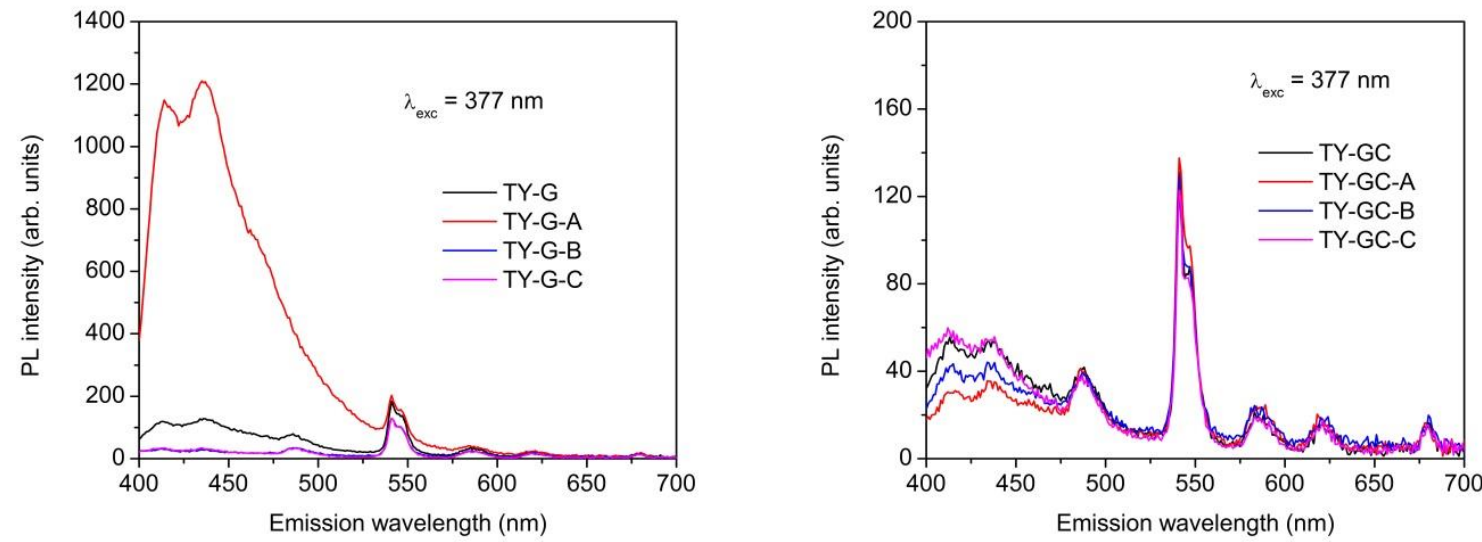

Figure 3: Photoluminescence emission spectra for the TY-G (left) and TY-GC (right) samples before and after Ag-exchange and annealing by exciting the sample at $377 \mathrm{~nm}$.

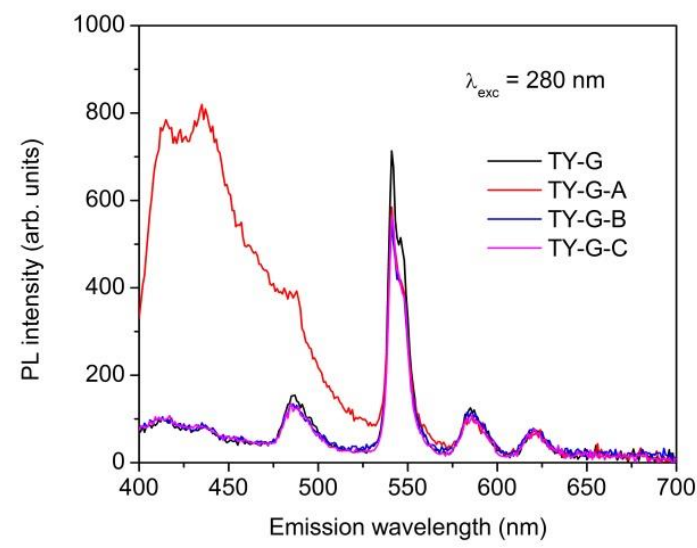

Figure 4: Photoluminescence emission spectra for the TY-G (left) and TY-GC (right) samples before and after Ag-exchange and annealing by exciting the sample at $280 \mathrm{~nm}$.
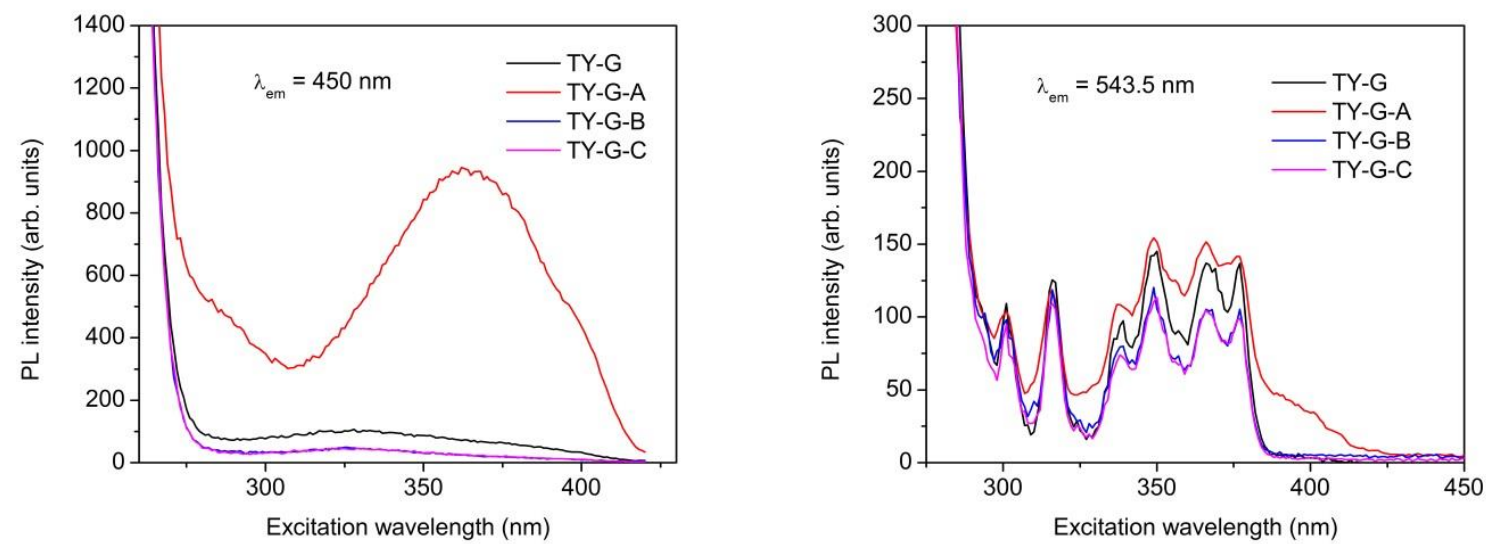
Figure 5: Photoluminescence excitation spectra for the TY-G samples at $450 \mathrm{~nm}$ (left) and $543.5 \mathrm{~nm}$ (right) before and after Ag-exchange and annealing.
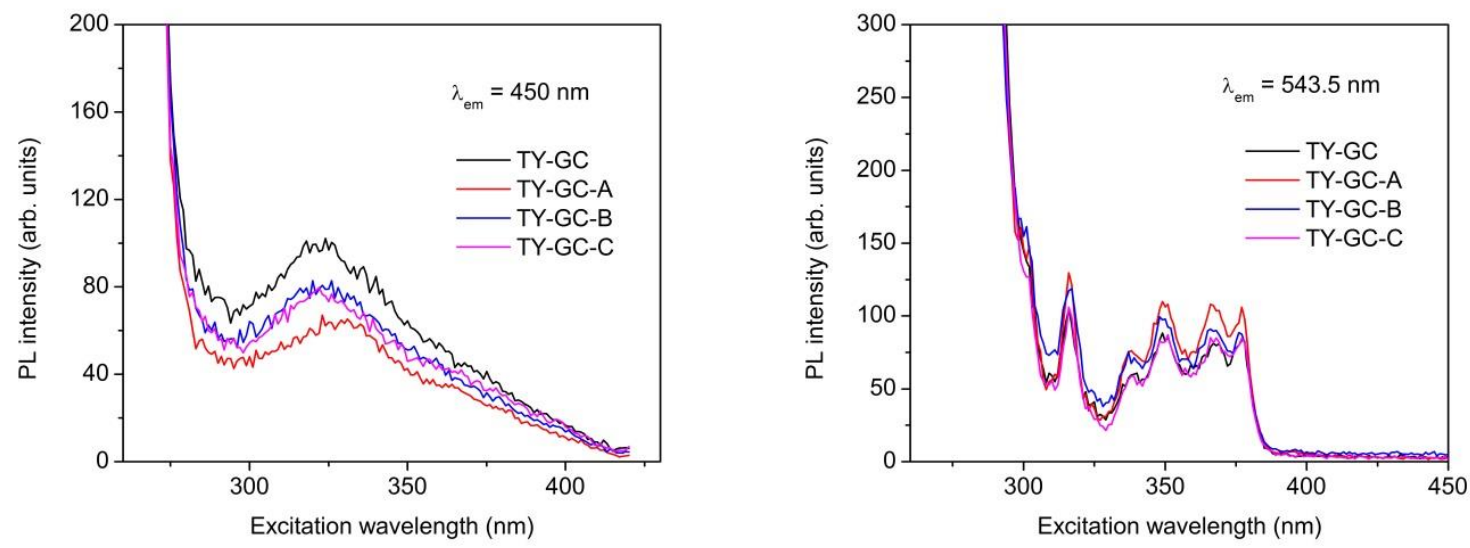

Figure 6: Photoluminescence excitation spectra for the TY-GC samples at $450 \mathrm{~nm}$ (left) and $543.5 \mathrm{~nm}$ (right) before and after Ag-exchange and annealing.

\section{Conclusions}

This paper reports the possibility to introduce $\mathrm{Ag}$ in $1 \% \mathrm{~Tb}^{3+}-4 \% \mathrm{Yb}^{3+}$ doped glass (G) and glass-ceramic (GC) sol-gel silica-hafnia waveguides by ion-exchange technique. The films were prepared by sol-gel deposition, annealing at $900^{\circ} \mathrm{C}(\mathrm{G})$ or $1000^{\circ} \mathrm{C}(\mathrm{GC})$ and subsequent ion-exchange in a molten salt bath followed by a final thermal treatment in air at $380^{\circ} \mathrm{C}$ or $440^{\circ} \mathrm{C}$. RBS and SIMS analyses showed the successful introduction of $\mathrm{Ag}$ for the $\mathrm{G}$ films, and the total amount was evaluated in only 0.2 at.\%. Moreover, the following thermal treatments further reduce the $\mathrm{Ag}$ amount at $40 \%$ of the starting value. On the contrary, $\mathrm{Ag}$ was not detected in the GC films. PL analysis of the as-exchanged G sample evidenced a strong broadband UV excitation centred at $365 \mathrm{~nm}$ and extending up to $420 \mathrm{~nm}$, responsible for an intense blue emission, which can be reasonably ascribed to isolated $\mathrm{Ag}+$ or $\mathrm{Ag}+-\mathrm{Ag}+$ dimers. This emission completely disappears after annealing for the reduction of the $\mathrm{Ag}$ amount and/or changing of $\mathrm{Ag}$ aggregation form, and was not detected at all in GC samples. Controlling the spectral features of this band and combining it with absorption and emission of other rare earths like $\mathrm{Tb}$ and $\mathrm{Yb}$ could be very interesting for increasing solar cells efficiency by downshifting UV radiation into the visible and more. Further work will be focused on increasing the Ag concentration in the films to better clarify the role and the effect of this element and its interaction with the rare earth ions.

\section{Acknowledgments VERIFICARE}

The research activity was performed in the framework of the CNR-CNRST joint project (2014-2015), CNRPAS joint project (2014-2016), and COST Action MP1401 (2014-2018)

AGGIUNGERE ANCHE PROGETTO PLANS???.

\section{References}

[1] M. A. Green, Third generation photovoltaics: advanced solar energy conversion, Berlin Heidelberg: Springer-Verlag, 2003.

[2] C. e. a. Strumpel, "Modifying the solar spectrum to enhance silicon solar cell efficiency - An overview of available materials," Solar Energy Materials and Solar Cells, vol. 91, no. 4, pp. 238249, 2007. 
[3] B. S. Richards, "Luminescent layers for enhanced silicon solar cell performance: downconversion," Solar Energy Materials and Solar Cells, vol. 90, no. 9, pp. 1189-1207, 2006.

[4] A. e. a. Shalav, "Luminescent layers for enhanced silicon solar cell performance: up-conversion," Solar Energy Materials and Solar Cells, vol. 91, no. 9, pp. 829-842, 2007.

[5] A. e. a. Meijerink, "Photon management with lanthanides," Optical Materials, vol. 28, no. 6-7, pp. 575-581, 2006.

[6] G. Liu and B. Jacquier, Spectroscopic properties of rare earths in optical materials, Berlin Heidelberg: Springer-Verlag, 2005.

[7] L. Guo, Y. Wang, W. Zeng, L. Zhao and L. Han, "Band structure and near infrared quantum cutting investigation of GdF3:Yb3+, Ln3+ ( $\mathrm{Ln}=\mathrm{Ho}, \mathrm{Tm}$, Er, Pr, Tb) nanoparticles," Phys.Chem. Chem. Phys., vol. 15, pp. 14295-14302, 2013.

[8] L. Aarts, . B. M. van der Ende and A. Meijerink, "Downconversion for solar cells in NaYF4 :Er,Yb," Journal of Applied Physics, vol. 106, pp. 023522 1-6, 2009.

[9] W. J. Park, S. J. Oh, J. K. Kim, J. Heo, T. Wagner and L. Strizik, "Down-conversion in Tm3+/Yb3+ doped glasses for multicrystalline silicon photo-voltaic module efficiency enhancement," Journal of Non-Crystalline Solids, vol. 383, pp. 181-183, 2014.

[10] D. H. Li, Y. J. Chen, J. H. Huang, X. H. Gong, Y. F. Lin, Z. D. Luo and Y. D. Huang, "Near-infrared down-conversion in $\mathrm{Pr} 3+-\mathrm{Yb} 3+$ co-doped transparent glass ceramic containing $\mathrm{Ca}$ ( $\mathrm{PO} 4) 3 \mathrm{~F}$ nanocrystals," Physica B, vol. 446, pp. 12-16, 2014.

[11] M. C. Gonçalves, L. F. Santos and R. M. Almeida, "Rare-earth-doped transparent glass ceramics," Comptes Rendus Chimie, vol. 5, no. 12, pp. 845-854, 2002.

[12] S. Ye, Y. Katayama and S. Tanabe, "Down conversion luminescence of Tb3+-Yb3+ codoped SrF2 precipitated glass ceramics," Journal of Non-Crystalline Solids, vol. 357, p. 2268-2271, 2011.

[13] S. Ye, B. Zhu, J. Chen, J. Luo and J. R. Qiu, "Infrared quantum cutting in Tb3+,Yb3+ codoped transparent glass ceramics containing CaF2 nanocrystals," Applied Physics Letters, vol. 92, pp. 141112 1-3, 2008.

[14] S. Berneschi, "Rare-earth-activated glass-ceramic waveguides," Optical Materials, vol. 32, pp. 1644-1647, 2010.

[15] Y. Jestin and e. al., "Erbium activated HfO2 based glass-ceramics for photonics," Journal of NonCrystalline Solids, vol. 353, pp. 494-497, 2007.

[16] Y. Jestin and e. al., "Low-loss optical Er3+-activated glass-ceramics planar waveguides fabricated by bottom-up approach," Applied Physics Letters, vol. 91, pp. 071909 1-3, 2007.

[17] G. Alombert-Goget and e. al., "Tb3+/Yb3+ co-activated Silica-Hafnia glass ceramic waveguides," Optical Materials, vol. 33, pp. 227-230, 2010.

[18] A. Bouajaj, S. Belmokhtar, M. R. Britel, C. Armellini, B. Boulard, F. Belluomo, A. Di Stefano, S. Polizzi, A. Lukowiak, M. Ferrari and F. Enrichi, "Tb3+/Yb3+ codoped silica-hafnia glass and glass- 
ceramic waveguides to improve the the efficiency of photovoltaic solar cells," Optical Materials, vol. 52, pp. 62-68, 2016.

[19] H. A. Atwater and A. Polman, "Plasmonics for improved photovoltaic devices," Nature Materials, vol. 9, pp. 205-213, 2010.

[20] M. Green and S. Pillai, "Harnessing plasmonics for solar cells," Nature Photonics, vol. 6, pp. 130$132,2012$.

[21] A. Martucci, M. De Nuntis, A. Ribaudo, M. Guglielmi, S. Padovani , F. Enrichi, G. Mattei, P. Mazzoldi, C. Sada, E. Trave, G. Battaglin, G. Gonella, E. Borsella, M. Falconieri, M. Patrini and J. Fick, "Silver-sensitized erbium-doped ion-exchanged sol-gel waveguides," Applied Physics A, vol. 80, no. 3, pp. 557-563, 2005.

[22] F. Enrichi, G. Mattei, C. Sada, E. Trave, D. Pacifici, G. Franzò, F. Priolo, F. lacona, M. Prassas, M. Falconieri and E. Borsella, "Evidence of energy transfer in an aluminosilicate glass codoped with Si nanoaggregates and Er3+ ions," Journal of Applied Physics, vol. 96, no. 7, pp. 3925-3932, 2004.

[23] A. Chiasera, M. Ferrari, M. Mattarelli, M. Montagna, S. Pelli, H. Portales, J. Zheng and G. C. Righini, "Assessment of spectroscopic properties of erbium ions in a soda-lime silicate glass after silver-sodium exchange," Optical Materials, vol. 27, no. 11, p. 1743-1747, 2005.

[24] F. Gourbilleau, C. Dufour, M. Levalois, J. Vicens, R. Rizk, C. Sada, F. Enrichi and G. Battaglin, "Room-temperature $1.54 \mu \mathrm{m}$ photoluminescence from Er-doped Si-rich silica layers obtained by reactive magnetron sputtering," Journal of Applied Physics, vol. 94, no. 6, pp. 3869-3874, 2003.

[25] C. Strohhofer and A. Polman, "Silver as a sensitizer for erbium," Applied Physics Letters, vol. 81, no. 8, pp. 1414-1416, 2002.

[26] M. Mattarelli, M. Montagna, K. Vishnubhatla, A. Chiasera, M. Ferrari and G. C. Righini, "Mechanisms of Ag to Er energy transfer in silicate glasses: A photoluminescence study," Physical Review B, vol. 75, pp. 125102 1-6, 2007.

[27] E. Cattaruzza, "Ag+ $\leftrightarrow \mathrm{Na}+$ ion exchanged silicate glasses for solar cells covering: down-shifting properties," Ceramics International, vol. 41, no. 5, pp. 7221-7226, 2015.

[28] T. G. Giallorenzi, E. J. West, R. Kirk, R. Ginther and R. A. Andrews, "Optical Waveguides Formed by Thermal Migration of Ions in Glass," Applied Optics, vol. 12, no. 6, pp. 1240-1245, 1973.

[29] R. V. Ramaswamy and R. Srivastava, "Ion exchanged glass waveguides: a review," Journal of Lightwave Technology, vol. 6, pp. 984-1002, 1988.

[30] S. I. Najafi, Introduction to Glass Integrated Optics, Boston-London: Artech House, 1992.

[31] E. Cattaruzza, M. Mardegan, E. Trave, G. Battaglin, P. Calvelli, F. Enrichi and F. Gonella, "Modifications in silver-doped silicate glasses induced by ns laser beams," Applied Surface Science, vol. 257, no. 12, pp. 5434-5438, 2011.

[32] A. Quaranta, A. Rahman, G. Mariotto, C. Maurizio, E. Trave, F. Gonella, E. Cattaruzza, E. Gibaudo and J. E. Broquin, "Spectroscopic investigation of structural rearrangements in silver ion- 
exchanged silicate glasses," Journal of Physical Chemistry C, vol. 116, no. 5, pp. 3757-3764, 2012.

[33] J. A. Jimenez, S. Lysenko, G. Zhang and H. Liu, "Optical properties of silver-doped aluminophosphate glasses," Journal of Materials Science, vol. 42, no. 5, pp. 1856-1863, 2007.

[34] E. Borsella, G. Battaglin, M. A. Garcia, F. Gonella, P. Mazzoldi, R. Polloni and A. Quaranta, "Structural incorporation of silver in soda-lime glass by the ion-exchange process: a photoluminescence spectroscopy study," Applied Physics A, vol. 71, pp. 125-132, 2000. 